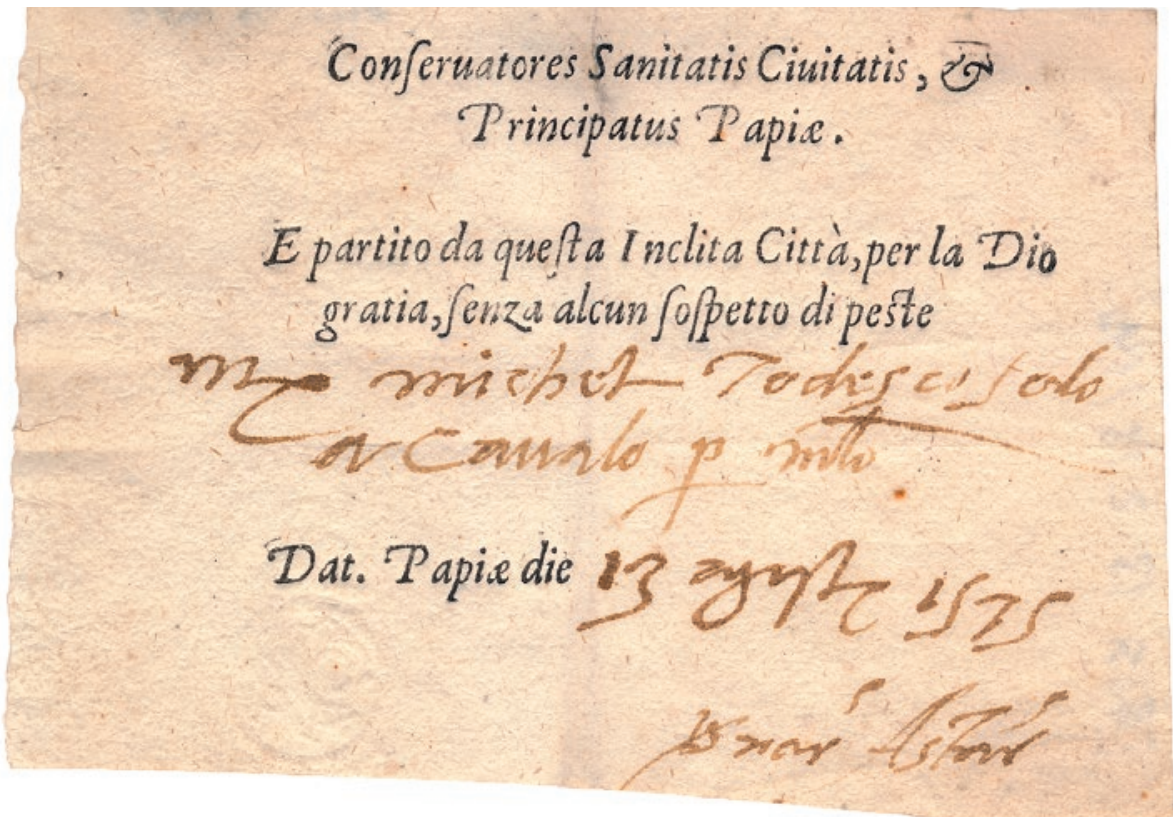

Reisen in der Pestzeit? Mit dem abgebildeten Passierschein durchaus möglich.

\title{
Ein Fluchthelfer aus Papier
}

\section{Iris Ritzmann}

Prof. Dr. med. et lic. phil., Mitglied der Redaktion Medizingeschichte

Erkennen Sie dieses medizinhistorische Objekt? Das amtliche Dokument wurde als Holzschnitt vorbedruckt und mit der Feder in brauner Tinte ausgefüllt. Es handelt sich um einen Gesundheitspass, einen Passierschein, den die staatlichen Gesundheitsschützer und die päpstliche Regierung am 13. August 1575 signiert hatten. Er bestätigt dem handschriftlich eingetragenen Besitzer, aus der Stadt abgereist zu sein und durch Gottes Gnade - keinen Verdacht einer Pest auf sich zu tragen.

Medizinisch begründete Einschränkungen des Personenverkehrs gehen bis in die Antike zurück und kamen mit dem Einfall des Schwarzen Todes in Europa wieder auf. Zwischen 1348 und 1352 erlagen, je nach Schätzungen, zwischen einem Zehntel und einem Drittel der europäischen Bevölkerung einem grossen Sterben. Danach wiederholten sich im Abstand von rund einem Dutzend Jahre neue Seuchenzüge, auch um 1575.

«Cite, longe, tarde.» Dieser wohl bekanntesten Empfehlung, bei Ausbruch einer Seuche schnell und weit weg zu fliehen und erst spät wieder zurückzukehren, versuchten viele Personen nachzukommen. Je unbekannter die Ursachen und Übertragungswege, desto grösser die Angst. Doch der Wegzug von einem Ort bedingt die Ankunft in einem nächsten. Welche Region aber wollte zu Pestzeiten eine Person bei sich empfangen, die mög-
Um dennoch Grenzen überschreiten zu können, benötigten die Reisenden Dokumente, die ihren Besitzerinnen und Besitzern bescheinigten, keine Krankheitszeichen aufzuweisen. Selbstverständlich öffneten sich Grenzen nicht aufgrund des tatsächlichen Gesundheitszustands. Abhängig von Rang und Namen, Beruf und Status sowie geleisteten Zahlungen ermöglichten Passierscheine, den Waren- und Personentransport aufrechtzuerhalten und die gutfreundschaftlichen Beziehungen zu benachbarten Regionen zu festigen.

Weder irgendwelche Beschränkungen von Handel oder Reisemöglichkeiten noch Räucherungen, Schutzmasken, Selbstkasteiungen, sexuelle Enthaltsamkeit oder Gebete zeitigten erkennbare Einflüsse auf die wiederholte Ausbreitung der Krankheit, mit der die europäische Bevölkerung während dreier Jahrhunderte lebte. Seit dem 18. Jahrhundert zog sie sich immer mehr zurück, wobei die Gründe bis heute unklar geblieben sind. Das Wissen um den Erreger Yersinia pestis, die Zwischenwirte und Übertragungswege, aber auch die Behandlung der heutigen Infektionskrankheit Pest haben jedenfalls nichts zum frühneuzeitlichen Rückzug der damaligen Seuche aus Europa beigetragen.

\section{Bildnachweis}

Gesundheitspass, Italien 1575. Holzschnitt, $77 \mathrm{~mm} \times 108 \mathrm{~mm}$. Archiv für Medizingeschichte der Universität Zürich, Signatur: AfM, BSa.13:2.15/14. 